\title{
LA SOCIEDAD COOPERATIVA COMO ESTRUCTURA JURÍDICA DE EMPRESA. UNA REFLEXIÓN A PROPÓSITO DEL ANTEPROYECTO DEL CÓDIGO MERCANTIL
}

\author{
Angélica Díaz de la Rosa \\ Titular de Universidad acreditada, \\ Escuela Universitaria de Relaciones Laborales y Recursos Humanos de A Coruña
}

DOI: $10.1387 /$ lan-harremanak.15415

\section{ABSTRACT}

La sociedad cooperativa posee una serie de caracteristicas propias que la hacen merecedora de un impulso constitucional a través de diversas actuaciones políticas y que se concretan en un conjunto de valores y principios que posibilita una participación democrática de los cooperativistas en la empresa cooperativa. A partir de este punto, lo que procede es que la regulación de este tipo societario sea tal que, sin menoscabo o perjuicio de los valores y principios mencionados, permita una óptima actuación en el mercado, en concurrencia con otras sociedades del mismo o de diverso tipo, $y$-en general - con cualquier operador económico.

Pues bien, la sociedad cooperativa permite, tal y como aparece recogido en el art. 1 de la LC, el desarrollo de cualquier actividad empresarial; es, pues, una forma adecuada para el desarrollo de una actividad económica organizada en términos de empresa. Pero no solo eso: el hecho de que la sociedad cooperativa tenga una estructura compleja, dotada de órganos, que estos órganos desempeñan funciones propias, nos conduce a la idea de racionalización, de organización compleja... que evoca a la propia empresa, de igual manera que sucede en las sociedades de capitales, podemos 
afirmar que nos encontramos ante una estructura que no solo es idónea para el desarrollo de una actividad empresarial, sino que ella misma es una auténtica estructura de empresa.

Palabras clave: cooperativas, organización empresarial, naturaleza jurídica, estructura societaria, mercantilidad, Anteproyecto Código Mercantil.

The cooperative has a number of characteristics that make it worthy of a constitutional impulse through various policies and actions that are specified in a set of values and principles that enables democratic participation of cooperative members in the cooperative enterprise. From this point on, the next step is that the regulation of this type of company is such that, without detriment or prejudice of the values and principles mentioned, allows optimal performance in the market, in competition with other companies in the same or different type, and generally - in any economic operator.

So, the cooperative allows, as it appears reflected in the art. $1 \mathrm{LC}$, the development of any business; It is thus a form suitable for the development of an economic activity organized in terms of business. But not only that: the fact that the cooperative has a complex structure, with general meetings and boards that play own functions, leads to the idea of rationalization, complex organization ... reminiscent of the company, similarly to what happens in limited companies, we can say that we have a structure that is not only suitable for the development of a business, but she is a real business structure.

Key Words: cooperatives, business organization, legal status, corporate structure, commercial natural. 
El ente cooperativo, que permite la asociación de personas para la promoción de un fin común de carácter mutualista, trata de satisfacer las necesidades y aspiraciones comunes que presentan sus socios. Esta finalidad se consigue a través de una fórmula societaria con pleno encaje en el principio constitucional de libertad de empresa, ya que la cooperativa no es más — ni menos- que una de las formas jurídicas societarias por la que pueden optar los distintos operadores económicos para realizar las actividades que les son propias, debiendo despojarla de antiguas ideologías políticas, que han lastrado a este tipo societario durante muchas décadas. Concibiendo a las sociedades cooperativas desde una perspectiva más aséptica y técnica permitiremos que resulten más eficientes y que tengan un mayor desarrollo.

Consciente de esta realidad, el legislador cooperativo se proyecta en la dirección apuntada $\mathrm{y}$, progresivamente, ha ido dotando a la sociedad cooperativa de distintos mecanismo que le han permitido crear una estructura más solida y adecuada a la dimensión de la empresa y, de este modo, concurrir al mercado en condiciones similares a las que lo hacen otras estructuras empresariales; adaptando esta fórmula organizativa a la realidad del tráfico; así, poco a poco, se ha ido aumentando el porcentaje de las operaciones con terceros no socios - que como es bien sabido, constituyen una auténtica extroversión del resultado y, por tanto, una mayor apertura al mercado-, relajando el principio de autogestión, permitiendo paulatinamente mayor presencia de una administración exógena a la propia cooperativa - algo que, por otra parte, se venía reclamando desde tiempo atrás por el sector cooperativo y que resulta perfectamente entendible si tenemos en cuenta todas las peculiaridades que presenta este tipo societario-, contemplando legalmente la posibilidad de crear cooperativas mixtas, etc.

Hecha esta precisión, podemos afirmar que la sociedad cooperativa posee una serie de características propias que la hacen merecedora de un impulso político, en el sentido constitucionalmente previsto: «Los poderes públicos promoverán eficazmente las diversas formas de participación en la empresa y fomentarán, mediante una legislación adecuada, las sociedades cooperativas». Este marbete constitucional que se le coloca a la cooperativa responde al convencimiento de que este tipo societario, impregnado de valores y principios, posibilita una participación democrática de los cooperativistas en la empresa cooperativa. A partir de este punto, lo que procede es que la regulación de este tipo societario sea 
tal que, sin menoscabo o perjuicio de los valores y principios mencionados, permita una óptima actuación en el mercado, en concurrencia con otras sociedades del mismo o de diverso tipo, y — en general — con cualquier operador económico.

Como es sabido, la finalidad de la sociedad cooperativa es satisfacer necesidades o aspiraciones comunes de sus socios y para la consecución de dicho fin se llevan a cabo actividades de índole empresarial. No cabe duda de que la sociedad cooperativa permite, tal y como aparece recogido en el art. 1 de la LC, el desarrollo de cualquier actividad empresarial, por lo que se perfila como una forma adecuada para el desarrollo de una actividad económica organizada en términos de empresa. Se lleva a cabo una organización compleja de los factores de producción - capital y trabajo- que proporciona bienes y servicios para el mercado. Se podría pensar que en el caso de la cooperativa esta extroversión del resultado solo se hace efectiva cuando se realizan operaciones con terceros no socios pero la verdad es que nada impide considerar que cuando la actividad colectivizada se desarrolle en exclusiva con y para los socios, ese "mercado" - aunque no se halle abierto al público en general - no puede estar constituido por ellos mismos, toda vez que — en definitiva - existe diferencia de identidad, entre la Cooperativa - como persona jurídica, con identidad propia- y unos socios suyos, que son sujetos de Derecho distintos de ella, y que pueden trabar con la Cooperativa relaciones jurídicas ajenas al ámbito de las relaciones estrictamente corporativas, internas o sociales.

Siendo ello así, tenemos que afirmar, apriorísticamente, que nos encontramos ante un tipo de sociedad que hemos de calificar como mercantil. Cuando nos enfrentamos a la tarea jurídica de determinar la naturaleza civil o mercantil de una sociedad tendremos que establecer, en primer término, cuál es el criterio que nos permite realizar tal distinción. Han sido múltiples los criterios empleados a lo largo de los tiempos para determinar la mercantilidad o civilidad de una materia, partiendo de criterios puramente subjetivos como la pertenencia a una clase o estatus determinado - el derecho de los mercaderes- a los criterios puramente objetivos que surgen tras la codificación, coherentes con la voluntad codificadora dirigida a superar la condición del Derecho mercantil como un derecho de clase, abriendo el ámbito de actuación a todas aquellas personas que, teniendo capacidad para ejercer el comercio, se dediquen a él de forma habitual, aunque para realizar tal extensión se recurrió a la técnica poco afortunada, la del acto de comercio como criterio objetivo para establecer la mercantilidad de la materia. Esta situación fue la que obligó a la doctrina y a la jurisprudencia a buscar un concepto de empresa - que se configura como concepto subyacente o vertebrador del principal que es el empresario- sobre el que construir ese criterio objetivo que determinará la mercantilidad de la materia. De este modo, la mercantilidad se hace girar sobre la titularidad de la empresa. 
El Anteproyecto del Código mercantil pretende aclarar definitivamente la cuestión y establece la mercantilidad desde una doble perspectiva: desde un punto de vista subjetivo - por razón de la persona- $-\mathrm{y}$, desde un punto de vista objetivo — por razón de la naturaleza de las operaciones-. Este último - el criterio objetivo - nos va a permitir la inclusión en el seno de la materia mercantil a otras personas que, no siendo empresarios desde el punto de vista económico y dada la naturaleza intelectual de los bienes que producen o de los servicios que prestan (científicos, artísticos, liberales) aparecen recogidos entre los operadores sujetos a este Código. En este sentido la Exposición de Motivos continua señalando que: "La delimitación de la materia se hace tanto del punto de vista subjetivo como objetivo. Partiendo de la doctrina del TC, de la doctrina cientifica moderna más autorizada, el mercado se concibe como ámbito en el que actúan los protagonistas del tráfico, cruzan ofertas y demandas de bienes y servicios, y entablan relaciones jurídico-privadas objeto de regulación especial. De esta manera, el Derecho mercantil vuelve a ser el Derecho de una clase de personas y de una clase de actividades, como lo fue en su origen, al que retornan las más modernas formulaciones positivas». Se diferencia, pues, entre el empresario y el operador de mercado, señalando, incluso, un sistema de fuentes diverso para cada uno de ello, de tal modo que, al empresario le resulta aplicable plenamente el estatuto mercantil, esto es, el conjunto de normas que establecen especiales derechos y obligaciones para las personas así calificadas, en función de la titularidad jurídica de una empresa y de la actividad que a través de ésta realiza para el mercado. En el estatuto se integran las normas sobre régimen jurídicoprivado de la empresa, responsabilidad y representación de su titular, registro mercantil y contabilidad, así como, en su conjunto, el Derecho de sociedades mercantiles. Ahora bien, estas normas legales especiales pueden extender su aplicación a los demás operadores del mercado incluidos en el ámbito subjetivo del Código de no existir otras que les sean específicamente aplicables por razón de la naturaleza de la persona, de la materia o de la índole de sus actividades.

En el ámbito societario, la mercantilidad también recorrió el mismo trayecto que el resto del cuerpo mercantil, si bien con ciertas peculiaridades propias de la materia. En un momento, previo a la codificación, se empleaba un criterio subjetivo basado en la condición de mercaderes de los integrantes de la sociedad para, posteriormente, pasar a emplear los criterios objetivos de la codificación.

Centrándonos ahora, de nuevo, en la regulación actual - y no en la proyectada-, el vigente art 116 del C. de Com. establece:

«El contrato de compañía por el cual dos o más personas se obligan a poner en fondo común bienes, industria o alguna de estas cosas, para obtener ánimo de lucro, será mercantil, cualquiera que fuese su clase, siempre que se haya constituido con arreglo a las disposiciones de este Código.» 
Y por su parte, el art. 1665 del C. Civ. establece:

«La sociedad es un contrato por el cual dos o más personas se obligan a poner en común dinero, bienes o industria, con ánimo de partir entre sí las ganancias.»

El contenido de los artículos reproducidos es prácticamente idéntico, con lo que estaríamos ante un fenómeno jurídico unitario que es objeto de regulación por partida doble. Así, ambos conciben la sociedad como el compromiso de dos o más personas de poner en común bienes o industria para promover un fin común. De los preceptos citados, parece inferirse que el criterio para distinguir las sociedades civiles de las mercantiles ha de buscarse fuera de la esencia del Contrato de Sociedad. Y este criterio diferenciador es el formal; esto es, como señala el art. 116 del C. de Com., serían mercantiles aquellas sociedades que se constituyan con arreglo al C. de Com. Como señalaba el Prof. Garrigues: "La doctrina española, sin darse cabal cuenta de su razón, destaca la imposibilidad de distinguir en cuanto al fondo en una sociedad civil de una mercantil, y olvida que esta misma imposibilidad ocurre si se intenta distinguir cualquier contrato mercantil de su correlativo civil, atendiendo al contenido de las obligaciones. Las obligaciones contractuales son idénticas en la venta civil y en la mercantil y lo mismo pasa en el depósito y en el préstamo y en el mandato y en la sociedad. La especialidad del contrato mercantil no afecta nunca a la esencia del acto, sino a ciertos elementos adyacentes de naturaleza subjetiva, objetiva, real o formali.

Atendiendo al tenor literal del art. 116 del C. Com, conforme al cual «El contrato de compañia ... ...... será mercantil siempre que se constituya con arreglo a las disposiciones de este código», la pregunta que surge es determinar el alcance de la expresión "que se constituya con arreglo a las disposiciones de este código». Pudiera pensarse, que el carácter mercantil de las sociedades se lo confiere un criterio objetivo formal; el de adoptar alguna de las formas jurídicas previstas por el art. 122 del C. Com, esto es, alguna de las siguientes: sociedad regular colectiva, sociedad comanditaria simple o por acciones, sociedad de responsabilidad limitada y sociedad anónima. La utilización de este criterio de mercantilidad supondría afirmar la tipicidad de la sociedades, solo serían mercantiles si adoptan una de estas formas - criterio formal — pero esta posibilidad queda matizada por el propio artículo 122 cuando nos dice que pondrá adoptar «entre otras las siguientes formas societarias», por tanto, no se trata de una enumeración cerrada sino que se abre la posibilidad de introducir otras fórmulas societarias; si bien éstas no podrán ser absolutamente nuevas, sino una combinación de las características de las sociedades existentes, como señalaba el Prof. Sánchez Calero (Sánchez, 2003) esta afirmación ha de hacerse con cautela, ya que la creación de sociedades que no se ajusten a ninguno de los tipos legales previstos por las leyes, no puede quedar al arbitrio de la voluntad de las partes, ya que atenta contra las normas imperativas del Derecho de Sociedades 
en general y contra la seguridad del tráfico y de terceros. Lo que sí sería posible es la formación de subespecies sociales mediante la combinación o deformación de los tipos sociales existentes que tratan de atender las necesidades del tráfico económico.

Pero es más, si la intención del legislador del Código de Comercio fue establecer la mercantilidad sobre el criterio de la forma, hemos de decir que ha tenido muy poca virtualidad porque solo cuatro años después de la promulgación del C. Com, se promulga el C. Civ, y con él el art. 1670 que imposibilita la distinción entre sociedad civil y mercantil siguiendo el criterio formal al afirmar que «las sociedades civiles por el objeto al que se consagren podrán revestir forma mercantil» (Garrigues, 1947).

Descartado el criterio formal como regla para establecer la mercantilidad de las sociedades, se planteó que la expresión «con arreglo a las disposiciones de este código" se refería en realidad a los requisitos de constitución establecidos en el art. 119 del C. Com, me refiero al requisito de forma, escritura pública y al requisito de publicidad, inscripción en el Registro Mercantil. Sin embargo, una correcta interpretación de este precepto será entender que los requisitos que en él se exigen se establecen en orden a adquisición de la personalidad jurídica pero el contrato de sociedad, una vez cumplidos los requisitos del 1261 del C. Civ, existe y es válido, otra cosa será que, como consecuencia de la falta de personalidad jurídica, nos encontremos ante una sociedad irregular pero, en cualquier caso, la sociedad contrato es perfectamente válida.

Así las cosas, consideramos que el criterio más adecuado para establecer la mercantilidad de las sociedades es un criterio objetivo; es decir —al igual que se predica del empresario persona física del que afirmamos que es empresario porque es titular de la organización empresarial - la sociedad es mercantil porque la actividad constitutiva de su objeto social es mercantil. Sin embargo, esta última afirmación ha de ser matizada, ya que las actividades per se no son civiles ni mercantiles; esta condición la adquieren por la forma en que se desarrollan. Así, una actividad será mercantil —y por lo tanto, transmitirá esta mercantilidad a la sociedad - cuando se desarrolle en términos tales de organización, racionalización, división de trabajo, etc., que sea constitutiva de empresa (GarcíaPita, 2000). Será, pues, el concepto «empresa» — como fue señalado por el Prof. Girón Tena- el factor determinante de la mercantilidad del objeto social (Girón, 1976).

Una vez determinado que el criterio que resulta más adecuado para calificar a una sociedad como mercantil es el criterio objetivo de la empresa, debemos señalar que en el caso de las Sociedades Cooperativas el objeto social - como expresamente recoge el propio artículo 1 de la Lcoop- está constituido por «actividades empresariales» y, por lo tanto, esta organización empresarial de las 
actividades será la que comunique a la propia sociedad cooperativa su carácter mercantil.

Por su parte, el Anteproyecto de Código Mercantil, emplea un doble criterio para determinar la mercantilidad de las sociedades, a saber: el objetivo y el formal, que se aplican de forma diferenciada, esto es, la sociedad puede adquirir la mercantilidad por la vía de la forma o por la vía de la organización del objeto que desarrolla. La Exposición de Motivos establece que "Mas la titularidad de la empresa, criterio unitario para la calificación del empresario persona natural, no lo es para la persona jurídica, en el que junto al criterio de la naturaleza del objeto social se recoge el formal de la adopción de algún tipo de sociedad mercantill, entendiendo por empresa "...el conjunto de elementos personales, materiales e inmateriales organizadas por el empresario para el ejercicio de una actividad económica de producción de bienes o prestación de servicios para el mercado». De entrar en vigor el proyectado Código mercantil supondría el fin del criterio objetivo como único criterio para determinar la mercantilidad de las sociedades y que, por otro lado, es coherente con el establecido para determinar la mercantilidad de las personas físicas.

En la Exposición de Motivos se recoge de forma expresa que «El art. 211 del Anteproyecto establece que son sociedades mercantiles las que tienen por objeto la producción de bienes o la prestación de servicios para el mercado y, además, añade que serán mercantiles las sociedades, con independencia de su objeto, las que adopten alguna de las siguientes formas:
a) La sociedad colectiva.
b) La sociedad comanditaria simple.
c) La sociedad limitada.
d) La sociedad anónima.
e) La sociedad comanditaria por acciones.
f) La sociedad cooperativa.
g) La sociedad mutua de seguros.
h) Las sociedades de garantía recíproca.»

Como podemos observar, el Anteproyecto da un paso de gigante a la hora de determinar la naturaleza jurídica de la sociedad cooperativa, no se limita a abrir la posibilidad de que pudiésemos considerar la cooperativa como sociedad mercantil encuadrándola en el supuesto de sociedades por el objeto ,es decir, porque lleven a cabo producción o cambio de bienes o la prestación de servicios para el mercado, si no que, adopta una postura valiente y declara la mercantilidad de la sociedad cooperativa por la forma.

Se realiza una expresa atribución de mercantilidad a sociedades como la cooperativa, que por razones estrictas de oportunidad política se situaban 
extramuros de la materia mercantil, cuestión esta última que planteaba no pocos problemas a la hora de establecer su completo sistema de fuentes. En la Exposición de Motivos se justifica esta atribución de mercantilidad en el hecho de que se trata de tipos societarios que dan cobertura jurídica, con estructura corporativa, a actividades empresariales organizadas con base mutualística, con independencia de que su regulación este contenida en legislación propia fuera del Código. El anteproyecto no tiene, pues, una vocación totalizadora de la materia mercantil, si no que, en cierta medida, está reconociendo la posibilidad de que existan sociedades mercantiles que se encuentren reguladas por sus propias leyes, como es el caso de las sociedades cooperativas.

Pero no solo eso, sino que, la sociedad cooperativa en la medida en que se aleja de las sociedades con estructuras primarias, esto es, de aquellas sociedades que están pensadas para asociar a un número reducido de miembros (KRUBLER, 2001), vocacionalmente estable —en el sentido de que se da poca variación en la posición de socio- y que son esencialmente asociativas, en las que existe una organización sencilla muy próxima al esquema contractual; y se acerca, o es semejante, a aquellas otras sociedades que poseen una estructura compleja —en el sentido de que estamos ante sociedades dotadas de órganos y que estos órganos desempeñan funciones propias - nos conduce a la idea de racionalización, de organización compleja..... que, finalmente, evoca o sugiere la presencia de la propia empresa. De igual manera que sucede en las sociedades de capitales tradicionales, podemos afirmar que nos encontramos ante una estructura que, no solo es idónea para el desarrollo de una actividad empresarial, sino que, ella misma es una auténtica estructura de empresa. Así las cosas, podríamos afirmar que la cooperativa es, al igual que la anónima o la limitada, una sociedad mercantil por la forma, en el sentido de que su propia forma de organización definitoria de este tipo societario la convierte en una auténtica estructura de empresa.

Por otra parte, los propios riesgos generados por estas sociedades cooperativas, en cuanto que operadores económicos que llevan a cabo su actividad externa en el mercado en concurrencia con otras empresas, hacen que el Derecho Civil devenga insuficiente para ofrecer una protección adecuada a las terceras personas que estén relacionadas con las mismas. Surge así la necesidad material de una regulación mercantil, ya que el rigor mercantil está pensado para proteger los intereses de terceros que pueden verse defraudados, si el riesgo que comporta toda actividad mercantil no fuera contrapesado por especiales normas en materia de representación, responsabilidad, publicidad y protección del crédito. Es por ello, que estas sociedades están sometidas a la exigencia de los mismos requisitos que cualquier otro tipo de sociedad mercantil, esto es, están sometidas al estatus del empresario. 
La mercantilidad de las sociedades por la forma, tal y como se recoge en el artículo 211 del Anteproyecto del Código Mercantil implica dos cuestiones fundamentales:

- En primer lugar, el número de formas de personificación o de tipología de organización societaria $y$,

—En segundo lugar, el tema de lo que podríamos denominar "perímetro» de las sociedades y su extensión.

Sabemos que hay sociedades civiles y mercantiles, lo que quiere decir el art. 211 probablemente sea que las sociedades absolutamente inespecíficas, que podrían caber dentro de la sociedad civil — piénsese en la sociedad de ganancias o sociedad de goce...- si tienen un objeto mercantil, podrán considerarse incluidas dentro del perímetro de las sociedades mercantiles, pero no porque creen figuras atípicas, sino porque figuras típicas contempladas en el derecho común, pueden obtener la calificación de mercantiles por razón de su objeto. En el mejor de los casos, tal vez lo que haya sucedido es que, se haya venido a reconocer que puede existir una sociedad mercantil absolutamente genérica, que ni si quiera adopte la forma de sociedad colectiva y que quede sometida a un conjunto de normas comunes que constituyen la parte general del Derecho Mercantil de sociedades.

La entrada en vigor del Anteproyecto de Código Mercantil y con él la mercantilidad de las sociedades cooperativas, hará que resurjan antiguas disputas doctrinales acerca de la constitucionalidad de la regulación cooperativa por parte de las Comunidades Autónomas, ya que si estamos ante una materia mercantil indubitada y atendemos a lo establecido en el art. 149.1.6 de la Constitución, la competencia exclusiva para regular esta materia del corresponde al Estado. $\mathrm{Hu}$ biera sido deseable, como ya manifesté en otras ocasiones (Díaz, 2010), que el estado se hubiese reservado competencia para establecer las bases y principios de esta materia, permitiendo a las Comunidades Autónomas que la desarrollasen dando entrada a la idiosincrasia propia de cada Comunidad autónoma, de este modo, se establecería un marco común respetuoso con el principio de unidad de mercado y, al mismo tiempo, se daría la respuestas a las cuestiones específicas que se pueden plantear en cada territorio.

Situados ya, dentro de las sociedades mercantiles, la siguiente cuestión será establecer ante que tipo de sociedad mercantil nos encontramos, ¿se trata de una sociedad de personas o más bien, estaremos ante una sociedad de capitales?. Pues, bien, yo diría que nos encontramos con un tipo societario a medio camino entre las sociedades de personas y las sociedades de capitales, ya que podríamos afirmar que posee notas características de ambos tipos de sociedades (Tampoco podemos olvidar que históricamente la cooperativa pasó de ser una sociedad con posibilidad de establecer una responsabilidad ilimitada - lo que para algu- 
nos autores justifica la existencia, todavía hoy, de algún mecanismo cooperativo como por ejemplo la posible imputación de pérdidas a los socios cooperativosa una sociedad de responsabilidad limitada y que tras ese tránsito, todavía hay leyes autonómicas, como la de la Comunidad de Madrid, que confieren a los socios la libertad para optar entre estos dos sistemas de responsabilidad). En la cooperativa hay una estrecha relación entre la condición de socio y la aportación a capital, no olvidemos que es requisito necesario para adquirir la condición de socio realizar aportación a capital, esta circunstancia las aproxima a las sociedades de capital que se caracterizan por la existencia de una masa patrimonial que queda afecta a la sociedad como consecuencia de la técnica jurídica del capital social, frente a las sociedades de personas en las que lo que resulta relevante es el grupo de persona que la integran y en las que se centra tanto la garantía patrimonial - no hay incomunicación patrimonial entre el socio y la sociedadcomo la realidad de la personalidad jurídica.

En las sociedades cooperativas los socios no solo tienen el derecho si no, también, tienen la obligación de participar en la actividad económico-empresarial que lleva a cabo la cooperativa tendente a satisfacer las necesidades y aspiraciones sociales o económicas que presentan en común todos sus socios y que justifican el nacimiento de esta tipo societario. De tal modo que, las actividades económicas que constituyen el objeto social son desarrolladas por los propios socios cooperativos provocando así la mutualización del objeto social y que pasa a denominarse «actividad cooperativizada».

Ahora bien, para llegar a ser socio requiere — además de poseer las necesidades y aspiraciones comunes - un cierto procedimiento autorizatorio más propio de las sociedades de personas; aunque, a decir verdad, creo que no son ni lo uno ni lo otro, sino que se trata de sociedades que podemos denominar "genericistas» ya que lo realmente esencial para las cooperativas es el hecho de que nos encontramos ante un grupo, o de una asociación de personas, caracterizada o especificada por poseer unas necesidades o aspiraciones económicas o sociales comunes a todos ellos. Utilizando las palabras de Ortega y Gasset «Yo soy yo y mis circunstancias», lo que hemos de tomar en consideración en la cooperativa no es el "Yo» —entendido como referido a la condiciones personales/patrimoniales individuales y particulares del socio — sino «mis circunstancias» que se refieren a esas aspiraciones o necesidades que poseo en común con el resto de los miembros de la cooperativa.

El «Yo», de alguna manera queda cubierto con la técnica jurídica del capital social que adscribe el patrimonio a la sociedad, por lo que acaba perdiendo importancia para la sociedad cooperativa el patrimonio personal de cada socio - que resulta tan relevante en las sociedades de personas, ya que en última instancia constituyen la gantía de la propia sociedad - y deja paso a "mis circunstancias», como elemento constitutivo y diferenciador de este esquema societario, 
lo que realmente nos une son nuestras comunes necesidades o aspiraciones y la voluntad de satisfacerlas de forma colectiva desarrollando en común las actividades económicas que resulten precisas para tal fin.

\section{Bibiografía}

Díaz de la Rosa, A., 2010, El naviero cooperativo, Cizur Menor, Aranzadi.

García-Pita y Lastres, J.L., 2000, «Reflexiones sobre el concepto de Sociedad y el Derecho de Sociedades", en $C D C$, n. 33.

Garrigues Díaz-Cañabate, J., 1947, Tratado de Derecho Mercantil, T. I, Vol. I.o, Edit. Madrid, Revista de Derecho Mercantil.

Girón Tena, J., 1976, Derecho de Sociedades, T. I , Parte General. «Sociedades Colectivas y Comanditarias» Madrid.

Krubler, F., 2001, Derecho de sociedades, ed. 5.a, Madrid, Edit, Fundación Cultural del Notariado.

Sánchez Calero, F., 2003, Instituciones de derecho Mercantil, Madrid, McGraw Hill. 